\title{
DOS NUEVAS OBRAS DE SEBASTIÁN DE LLANOS VALDÉS
}

\author{
TWO NEW PAINTINGS OF \\ SEBASTIÁN DE LLANOS VALDÉS
}

\author{
ENRIQUe VAldivieso GonZÁlez \\ Universidad de Sevilla, España \\ enriquevaldivieso@hotmail.com
}

\begin{abstract}
Análisis y valoración de dos obras que se atribuyen Sebastián de Llanos Valdés, pintor sevillano activo en el segundo tercio del siglo XVII.

Palabras claves: Pinturas, Inmaculada, Sevilla, Cádiz, Anunciación, Sebastián de Llanos Valdés.

Analysis and evaluation of two works Sebastián de Llanos Valdes, Sevillian painter active in the second third of the seventeenth century, are attributed.

Keywords: Paintings, Inmaculate, Seville, Annunciation, Cadiz, Sebastián de Llanos Valdés.
\end{abstract}

Fue sin duda D. Sebastián de Llanos Valdés (hacia 1605-1677), uno de los pintores más importantes en Sevilla en el segundo tercio del siglo XVII. Un resumen de su vida, junto con una valoración de su producción conocida, dimos a conocer hace años ${ }^{1}$.

Tenemos ahora la ocasión de presentar dos obras inéditas de este artista, que por su excelente calidad, pueden incorporarse a su catálogo. La primera de

${ }^{1}$ VALDIVIESO, Enrique: Pintura barroca sevillana. Sevilla, 2003, pp. 308-316. Datos fundamentales sobre este artista fueron dados a conocer por KINKEAD, D.: "Nuevos datos sobre los pintores Sebastián de Llanos Valdés e Ignacio de Iriarte", Archivo Hispalense, 191, 1979, p. 121; ver también LLEÓ, Vicente: "El pintor Sebastián de Llanos Valdés", Revista de arte sevillano, 1, 1979, pp. 21-23. Obras inéditas suyas fueron dadas a conocer por ANGULO, Diego: "D. Sebastián de Llanos Valdés", Archivo Español de Arte, 1946, p. 309; también por GUERRERO LOVILLO, José: "Obras inéditas de D. Sebastián de Llanos Valdés", Archivo Español de Arte, 1947, p. 133 y por FERNÁNDEZ LÓPEZ José: "Dos obras inéditas de Sebastián del Llanos Valdés”, Laboratorio de Arte, 1996, p. 357. 
ellas es un espléndida Inmaculada de tamaño natural ${ }^{2}$, que se conserva en una colección particular sevillana. Es obra de notoria disposición compositiva que presenta una clara personalidad con respecto a los prototipos que con esta iconografía realizaron otros contemporáneos suyos, como su maestro Francisco de Herrera el Viejo, Zurbarán y Murillo. La figura de María está concebida con una solemne monumentalidad, pero al mismo tiempo está dotada de suaves efectos de movimiento y ondulación; por otra parte, los pequeños ángeles que la rodean, presentan movidas actitudes corporales y sobre todo rasgos faciales totalmente característicos de la producción de este artista. Uno de ellos, muestra una rama de palma como advocación mariana, y otro a la izquierda sostiene una filacteria donde se lee "Sin pecado original". De estos ángeles, el que está situado al pie de la Virgen y a la derecha, está exactamente repetido en la Inmaculada niña firmada por Llanos Valdés en 1665, que se conserva en una colección particular sevillana.

Con respecto a la figura de María, se reconocen también en ella rasgos faciales comunes en las presencias femeninas dentro de la producción de este artista, que en este caso tienden a plasmar una elegante y discreta belleza. La melena que envuelve su rostro cae ondulante hasta la mitad de su espalda. Lleva túnica blanca y manto azul, advirtiéndose que este último se mueve aparatosamente a la izquierda de su silueta.

La fecha aproximada que puede otorgarse a esta obra puede situarse hacia 1670, en unos momentos en que el estilo de Llanos Valdés había alcanzado ya su total plenitud.

En la Real Capilla de Nuestra Señora del Pópulo de Cádiz, y en su espléndido retablo mayor, obra de mediados del siglo XVII, se conserva en el registro central de su segundo cuerpo, una magnífica representación pictórica de la Anunciación ${ }^{3}$, obra que hasta el presente sólo había sido mencionada en su lugar de origen sin haberse realizado nunca valoración alguna de su elevada calidad técnica ${ }^{4}$.

Esta pintura presenta figuras de tamaño natural con rasgos físicos y expresiones propias de Llanos Valdés, tanto en la presencia del arcángel San Gabriel como en la de la Virgen y de los pequeños ángeles músicos que revolotean en la parte superior de la composición. Con respecto al arcángel, puede señalarse que presenta unas características compositivas y un dibujo totalmente próximos a las

${ }^{2}$ Lienzo, mide $198 \times 11 \mathrm{~cm}$.

${ }^{3}$ Mide aproximadamente $200 \times 170 \mathrm{~cm}$.

${ }^{4}$ En todo caso, J. y L. Lorenzo de la Peña y P. Pomar, sugieren en la Guía de Cádiz y su provincia, vol. I, 2005, p. 55, que esta Anunciación junto con una Caída de San Pablo y un San Martín partiendo la capa con el pobre, pudieran ser obras de Juan Gómez Couto, que fue el dorador del retablo. Estas dos últimas pinturas se encuentran sucia y muy oscurecidas y su calidad no puede ser valorada. Si puede ser bien estudiada la mencionada Anunciación, que es en nuestro criterio obra de Llanos Valdés. 
del ángel en el Sacrificio de Isaac conservado en la sacristía de la iglesia del Salvador de Sevilla, firmada por Llanos Valdés.

Admirables son en esta Anunciación las calidades cromáticas que se integran en los vestuarios de los personajes y que están perfectamente coordinadas, así los tonos amarillos, rojos y verdes que figuran en la túnica, la camisa y el manto del arcángel, conjugan de manera admirable con la expresión de su figura. Esta está resuelta en una aparente verticalidad, pero desde los pies hasta la cabeza hay en ella un movimiento ondulatorio y una ligereza, que traspone la dinámica de una figura que viniendo del espacio, acaba de posar sus pies en la tierra. El mismo concepto de verticalidad se aprecia en la figura de la Virgen, que arrodillada recibe el anuncio de su mensajero. Lleva túnica rosácea y manto azul, con tonos perfectamente armonizados. Bien resueltos están los detalles ambientales que animan la escena, como el jarrón de bronce con azucenas que aparece entre San Gabriel y María.

Al fondo de la escena, el artista ha colocado una balaustrada de cuyo basamento arrancan dos pilares que con su verticalidad, refuerzan el sentido compositivo que Llanos Valdés ha querido otorgar a la escena.

La fecha que puede otorgarse a esta obra puede situarse aproximadamente en torno a 1660 , momentos en los que este pintor estaba ya consagrado en el ambiente artístico sevillano.

Fecha de recepción: 20 de septiembre de 2014

Fecha de aceptación: 28 de noviembre de 2014 


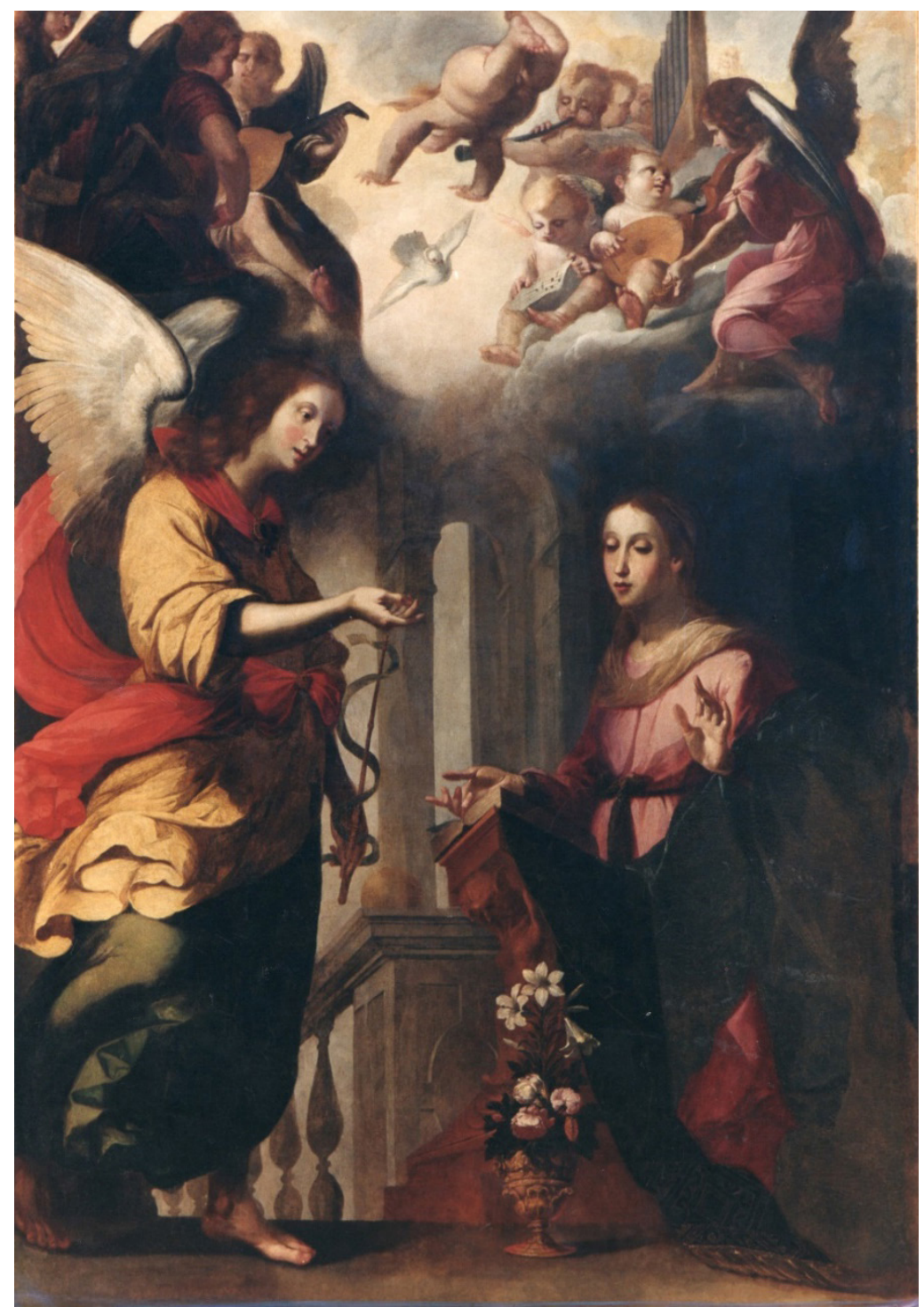

Figura 1. Sebastián de Llanos Valdés.

Anunciación. Cádiz. Real Capilla de Nuestra Señora del Pópulo. 


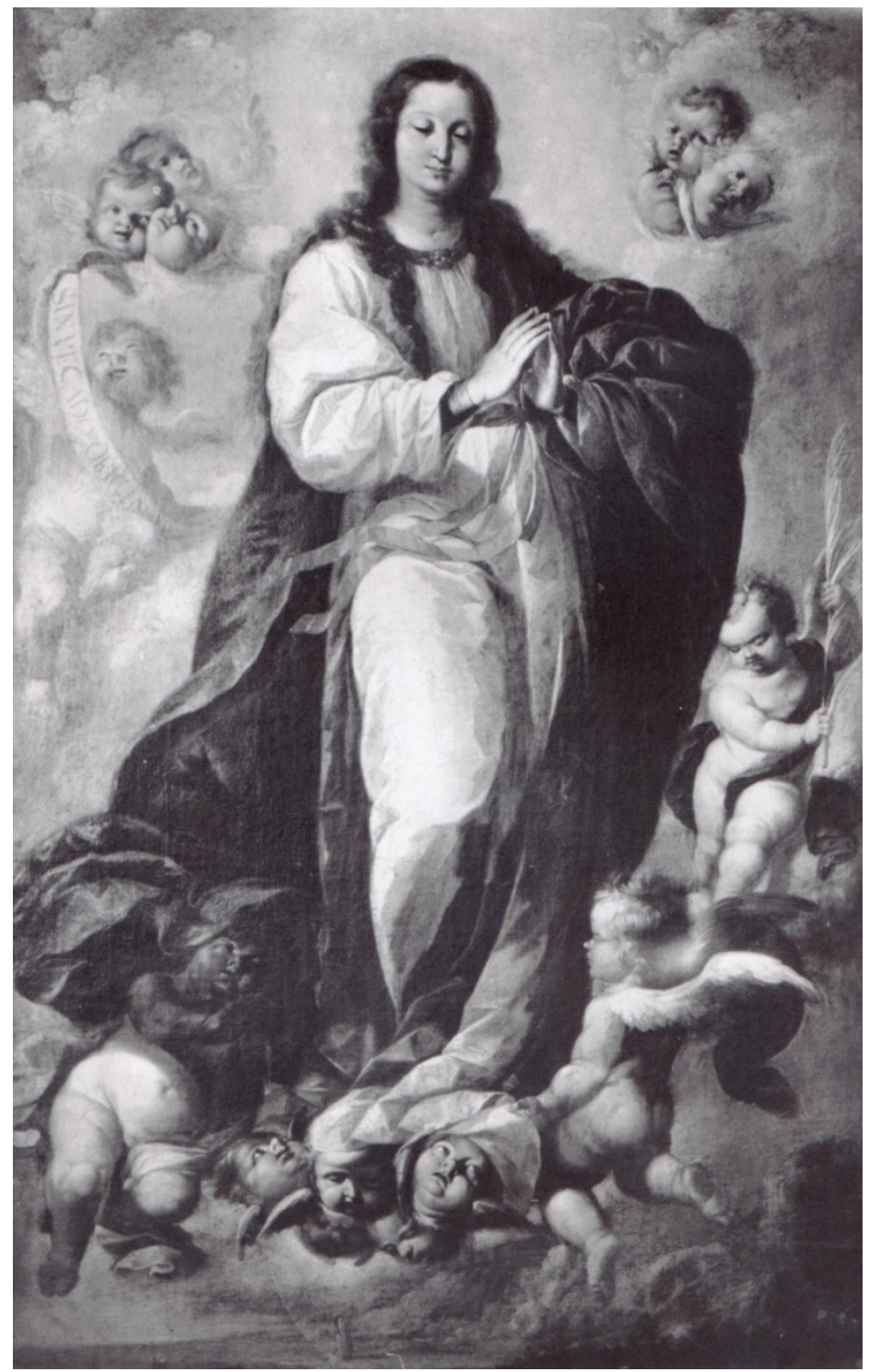

Figura 2. Sebastián de Llanos de Valdés. Inmaculada. Sevilla. Col. particular. 


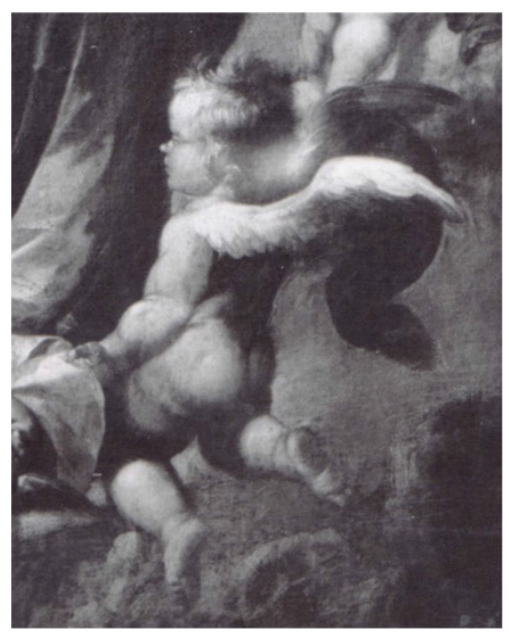

Figura 3.

Sebastián de Llanos de Valdés. Detalle de la Inmaculada. Sevilla. Col. particular.

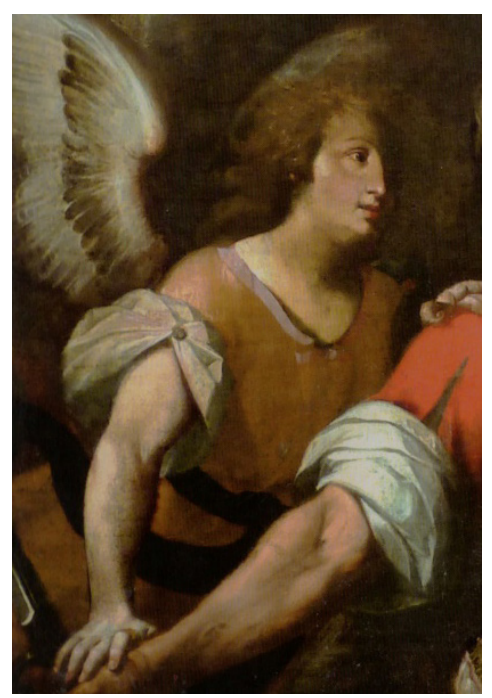

Figura 5.

Sebastián de Llanos de Valdés.

Sacrificio de Isaac (detalle).

Sevilla. Iglesia del Salvador.

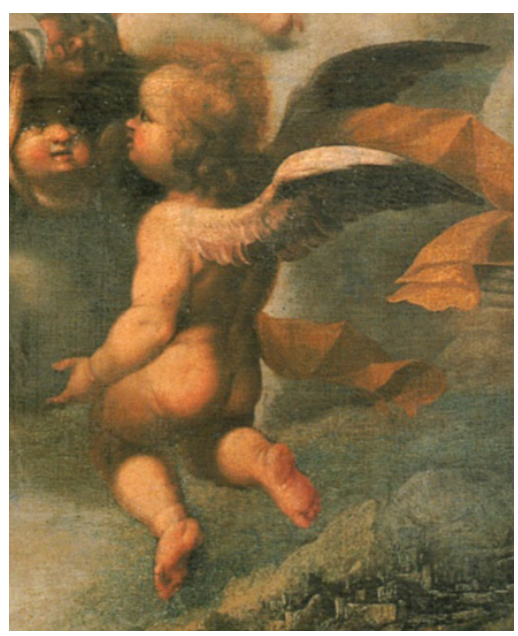

Figura 4.

Sebastián de Llanos de Valdés. Detalle de la Inmaculada niña. Sevilla. Col. particular.

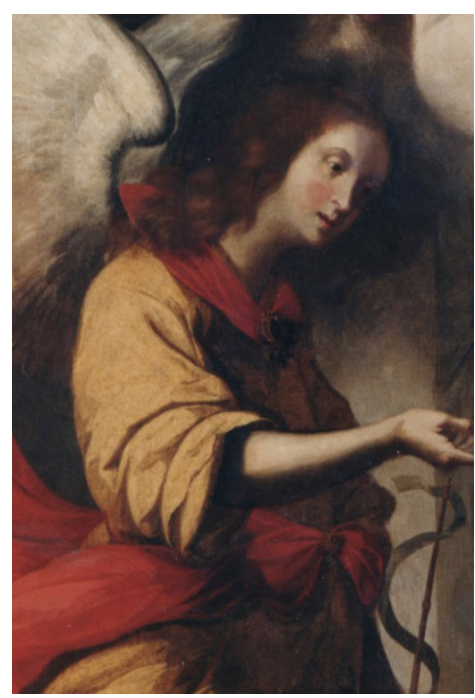

Figura 6.

Sebastián de Llanos de Valdés. Anunciación (detalle).

Cádiz. Capilla N. S. del Pópulo. 